\title{
A Grey Target Group Decision Method with Dual Hesitant Fuzzy Information considering Decision-Maker's Loss Aversion
}

\author{
Yufeng Zhou $\mathbb{D D}^{1,2}$ Yufeng $\mathrm{Li}^{3}$ and $\mathrm{Zhi} \mathrm{Li}^{1}$ \\ ${ }^{1}$ Chongqing Engineering Technology Research Center for Information Management in Development, \\ Chongqing Technology and Business University, Chongqing, China \\ ${ }^{2}$ Postdoctoral Research Station of Management Science and Engineering, Nanjing University of Aeronautics \& Astronautics, \\ Nanjing 211106, China \\ ${ }^{3}$ Research Center for Economy of Upper Researches of the Yangtze River, Chongqing Technology and Business University, \\ Chongqing, China
}

Correspondence should be addressed to Yufeng Zhou; xtuzyf@qq.com

Received 19 September 2019; Revised 19 January 2020; Accepted 8 June 2020; Published 29 June 2020

Academic Editor: Kifayat Ullah Khan

Copyright (C) 2020 Yufeng Zhou et al. This is an open access article distributed under the Creative Commons Attribution License, which permits unrestricted use, distribution, and reproduction in any medium, provided the original work is properly cited.

The uncertainty, complexity, and behavioral preference are widely existing in real-world decision-making problems. In this paper, different from the previous grey target decision method, we propose a novel grey target group decision method considering decision-maker's loss aversion with positive and negative clouts under the dual hesitant fuzzy environment. Firstly, defining the dual hesitant fuzzy ideal optimization scheme as the positive clout and the ideal inferior scheme as the negative clout, positive and negative target-eye distances are measured by the normalized Hamming distances from the DHFEs to the positive clout and the negative clout. Then, a new comprehensive target-eye distance is proposed to evaluate alternatives between the positive and the negative clout. A nonlinear optimization model is established to obtain the optimal initial attribute weights with the goal of minimizing the comprehensive target-eye distance. Then, a grey target group decision method with dual hesitant fuzzy information considering decision-maker's loss aversion and variable weights is proposed. Finally, a numeral example is given to verify the effectiveness and practicality of the proposed model and method.

\section{Introduction}

Multiattribute decision-making (MADM) is an important issue of modern decision-making science. Recently, MADM has become a hotspot in the decision-making area, and a lot of academic achievements have been made in the related domain [1-3]. Multiattribute group decisionmaking (MAGDM) can use the wisdom of the group to promote scientific decision-making. Pattern matching optimization is an effective method, which is applied to many areas in MAGDM, such as tracking and detection $[4,5]$, computer engineering [6], physical sciences [7], health-related issues [8], natural sciences, and industrial academic areas [9]. In addition, other methods, such as TOPSIS [10, 11], probabilistic linguistic term sets [12], data-capturing devices [13-17], the state-of-the-art features
[18-22], the hidden Markov model (HMM), modified HMM, embedded HMM, Gaussian mixture modal (GMM), and the support vector machine (SVM) are also widely used in the field of MAGDM [23-26]. Grey target decision is one of the main methods using grey system theory to solve the problem of uncertain MADM and MAGDM under incomplete information condition. The main idea of the grey target decision is to achieve a uniform dimension of the Euclidean space through measuring and transforming index sets in the absence of the standard mode, i.e., the grey target. All the alternatives are distributed on the grey target. A target-eye of the grey target is found as the standard mode. Then, all the decision points in the grey target are compared with the target-eye to obtain relative target-eye distances, and the dominant position of each decision point is sorted by the target-eye distances. 
In recent years, many scholars have carried out theoretical research on the classic grey target decision methods from different perspectives. Gupta et al. [27] presented an extended TOPSIS method under the interval-valued intuitionistic fuzzy environment. Luo and Wang [28] studied the multiattribute grey target decision method for the attribute value within the three-parameter interval grey number. Wang et al. [29] studied the multiattribute grey target decision method based on soft set theory. Qian et al. [30] built a grey target decision model based on interval grey number panel data for multiindex dynamic problems. Ye [31] proposed an extended TOPSIS method with interval-valued intuitionistic fuzzy numbers for virtual enterprise partner selection. Fu et al. [32] presented a kind of multiattribute grey target decision model based on the positive-negative target center aimed at the complexity and uncertainty of the actual decision environment. Zeng et al. [33] proposed a grey target decision-making model based on the cobweb area and gave an application of choosing the software development pattern.

Fuzzy sets (FSs) are also an effective method to deal with the uncertain problem of decision-making. FSs are used to deal with vagueness and fuzziness in real decisionmaking problems, and several extensions have been developed. Rodriguez et al. [34] studied the hesitant fuzzy linguistic term set on MADM. Traditional hesitant fuzzy decision-making methods just provide the membership degrees and without considering the importance of the nonmembership degrees. In fact, the nonmembership plays the same important role in describing the vague decision-making information, which indicates the possible degrees of one element does not belong to a fixed set. To assess the attribute values more precisely, Zhu et al. [35] developed the dual hesitant fuzzy set (DHFS), taking into account much more information given by decisionmakers, in which the membership degree and the nonmembership degree are in the form of sets of values in $[0,1]$. DHFS can avoid information distortion and losing effectively in describing the vague decision-making information. Then, the aggregation operators for aggregating dual hesitant fuzzy elements (DHFEs) have attracted the attention from researchers [36-40]. Regarding the MADM problems with dual hesitant fuzzy information, many methods have been proposed. Ren and Wei [41] developed a prioritized multiattribute decision-making method to solve dual hesitant fuzzy decision problems. Then, they [42] further proposed a dual hesitant fuzzy VIKOR method for multicriteria group decision-making based on the fuzzy measure and the new comparison method. Wei et al. [43] investigated the MADM problem based on the geometric aggregation operators with interval-valued dual hesitant fuzzy linguistic information. Lu and Wei [44] investigated the MADM problem based on the arithmetic and geometric aggregation operators with dual hesitant fuzzy uncertain linguistic information.

Based on the above analysis, we can conclude that the current studies on the DHFS are mainly based on some aggregation operators which are limited to tackle the complex MAGDM problem under the dual hesitant fuzzy environment. Therefore, other classical uncertain decision methods such as the grey target decision method should be further studied for real decision-making problems under dual hesitant fuzzy information. Therefore, the grey target decision method based on positive and negative clouts proposed is extended to solve the MAGDM problems with dual hesitant fuzzy information. It is the major motivation of our study. To the best of our knowledge, the existing grey target decision-making method has not yet been accommodated to deal with the dual hesitant fuzzy information provided by decisionmakers. In addition, the current research on the grey target decision method has also not considered the decision-maker's loss aversion. With the development of behavioral decision theory, the MAGDM method has been widely used on the basis of prospect theory. Therefore, the proposed model considers decisionmaker's loss aversion and variable weights of attributes based on the prospect theory. The contributions of this paper can be summarized as follows. (i) We proposed a novel grey target group decision method with positive and negative clouts under the dual hesitant fuzzy environment. (ii) We introduce the prospect theory to the grey target group decision.

The remainder of this paper is structured as follows. Section 2 presents the preliminaries of DHFS and DHFEs. Section 3 is the process of establishing the mathematical models. A numerical example is presented in Section 4 followed by conclusions in Section 5 .

\section{Preliminaries}

In this section, some essential concepts are reviewed as follows [36].

Definition 1. Let $X$ be a given set, DHFS; $D$ is a function mapping to $X$ :

$$
D=\{\langle x, h(x), g(x)\rangle \mid x \in X\} .
$$

In expression (1), $h(x)$ and $g(x)$ are two sets of numbers within the interval $[0,1] . h(x)$ and $g(x)$, respectively, denote the possible membership degrees and nonmembership degrees under the following conditions:

$$
0 \leq r, \eta \leq 1,0 \leq r^{+}+\eta^{+} \leq 1,
$$

where $r \in h(x), \eta \in g(x), r^{+} \in h^{+}(x)=\cup_{r \in h(x)} \max \{r\}$, and $\eta^{+} \in g^{+}(x)=\cup_{\eta \in g(x)} \max \{\eta\}$ for all $x \in X$. The pair $d(x)=$ $\langle h(x), g(x)\rangle$ is called the DHFE, which can be denoted simply by $d=\langle h, g\rangle$.

Obviously, if there is only one element in both $h(x)$ and $\mathrm{g}(x)$, the DHFE reduces to an intuitionistic fuzzy number.

Definition 2 (see [34]). Let $d_{1}=\left\langle h_{1}, g_{1}\right\rangle$ and $d_{2}=\left\langle h_{2}, g_{2}\right\rangle$, respectively, denote two DHFEs; then, the operational laws can be defined as 


$$
\begin{aligned}
d_{1} \oplus d_{2} & =\left\langle U_{r_{1} \in h_{1}, r_{2} \in h_{2}, \eta_{1} \in g_{1}, \eta_{2} \in g_{2}}\left\{\left\{r_{1}+r_{2}-r_{1} r_{2}\right\},\left\{\eta_{1} \eta_{2}\right\}\right\}\right\rangle, \\
d_{1} \otimes d_{2} & =\left\langle U_{r_{1} \in h_{1}, r_{2} \in h_{2}, \eta_{1} \in g_{1}, \eta_{2} \in g_{2}}\left\{\left\{r_{1} r_{2}\right\},\left\{\eta_{1}+\eta_{2}-\eta_{1} \eta_{2}\right\}\right\}\right\rangle, \\
\lambda d_{1} & =\left\langle U_{r_{1} \in h_{1}, \eta_{1} \in g_{1}}\left\{\left\{1-\left(1-r_{1}\right)^{\lambda}\right\},\left\{\left(\eta_{1}\right)^{\lambda}\right\}\right\}\right\rangle, \quad \lambda>0, \\
d_{1}^{\lambda} & =\left\langle U_{r_{1} \in h_{1}, \eta_{1} \in g_{1}}\left\{\left\{\left(r_{1}\right)^{\lambda}\right\},\left\{1-\left(1-\eta_{1}\right)^{\lambda}\right\}\right\}\right\rangle, \quad \lambda>0 .
\end{aligned}
$$

Definition 3 (see [43]). Let $d_{i}=\left\langle h_{i}, g_{i}\right\rangle(i=1,2, \ldots, n)$ denote a collection of DHFEs; then, the score function $S\left(d_{i}\right)$ and the accuracy function $P\left(d_{i}\right)$ of $d_{i}(i=1,2, \cdots, n)$ can be defined as

$$
\begin{aligned}
& S\left(d_{i}\right)=\frac{1}{\# h} \sum_{r \in h} r-\frac{1}{\# g} \sum_{\eta \in g} \eta, \\
& P\left(d_{i}\right)=\frac{1}{\# h} \sum_{r \in h} r+\frac{1}{\# g} \sum_{\eta \in g} \eta,
\end{aligned}
$$

where $\# h$ and $\# g$ are the number of values in $h(d i)$ and $g(d i)$, respectively.

Theorem 1 (see [45]). Let $d_{1}=\left\langle h_{1}, g_{1}\right\rangle$ and $d_{2}=\left\langle h_{2}, g_{2}\right\rangle$ denote two DHFEs, and they can be compared according to the following rulesfollowing rules:

$$
\begin{aligned}
& \text { if } S\left(d_{1}\right)>S\left(d_{2}\right) \text {, then, } d_{1}>d_{2}, \\
& \text { if } S\left(d_{1}\right)=S\left(d_{2}\right) \text {, then : } \\
& \text { if } P\left(d_{1}\right)>P\left(d_{2}\right) \text {, then } d_{1}>d_{2}, \\
& \text { if } P\left(d_{1}\right)=P\left(d_{2}\right) \text {, then } d_{1}=d_{2} \text {. }
\end{aligned}
$$

Definition 4 (see [46]). Let $d_{1}=\left\langle h_{1}, g_{1}\right\rangle$ and $d_{2}=\left\langle h_{2}, g_{2}\right\rangle$ be two DHFEs. The normalized Hamming distance is defined as

$$
d\left(d_{1}, d_{2}\right)=\frac{1}{2}\left(\left|\frac{1}{\# h_{1}} \sum_{r_{1} \in h_{1}} r_{1}-\frac{1}{\# h_{2}} \sum_{r_{2} \in h_{2}} r_{2}\right|+\left|\frac{1}{\# g_{1}} \sum_{\eta_{1} \in g_{1}} \eta_{1}-\frac{1}{\# g_{2}} \sum_{\eta_{2} \in g_{2}} \eta_{2}\right|\right),
$$

where $\# h_{i}$ and $\# g_{i}(i=1,2)$ are the number of values in $h_{i}$ and $g_{i}$, respectively.

\section{A Grey Target Decision Method for MAGDM Problems with Dual Hesitant Fuzzy Information and Decision-Maker's Loss Aversion}

In this section, a grey target decision method based on positive and negative clouts is developed to solve the MAGDM problem under the dual hesitant fuzzy environment and uncertain weight information.

Let $A=\left\{A_{1}, A_{2}, \cdots, A_{m}\right\}$ be a finite set of $m$ alternatives and $C=\left\{C_{1}, C_{2}, \cdots, C_{n}\right\}$ be the set of $n$ attributes. Let $\mathrm{DM}=$ $\left\{\mathrm{DM}_{1}, \mathrm{DM}_{2}, \cdots, \mathrm{DM}_{k}\right\}$ be the set of decision-makers whose weight vector is $\lambda=\left\{\lambda_{1}, \lambda_{2}, \cdots, \lambda_{k}\right\}^{T}$ such that $\lambda_{f} \in[0,1]$ and $\sum_{f=1}^{k} \lambda_{f}=1$. Suppose that $D f=\left(d_{i j}^{f}\right)_{m \times n}$ is a dual hesitant fuzzy decision matrix given by $\mathrm{DM}_{f}$, where $d_{i j}^{f}=$ $\left.<h_{i j}^{f}, g_{i j}^{f}\right\rangle$ denotes the DHFEs for the evaluation of the attribute $C_{j}(j=1,2, \cdots, n)$ with respect to the alternative $A_{i}(i=1,2, \cdots, m)$, with $h_{i j}^{f}=\cup_{r_{i j}^{f} \in h_{i j}^{f}}\left(r_{i j}^{f}\right)$ and $g_{i j}^{f}=\cup_{\eta_{i j}^{f} \in g_{i j}^{f}}$ $\left(\eta_{i j}^{f}\right)$. Then, to determine the most desirable alternatives, a novel method is proposed based on the grey target decision method with positive and negative clouts.

Step 1. Aggregate all individual dual hesitant fuzzy decision matrices $D f=\left(d_{i j}^{f}\right)_{m \times n}(i=1,2, \cdots, m, j=1,2, \cdots, n, \quad f=$ $1,2, \cdots, k)$ into a collective dual hesitant fuzzy decision matrix by the following equation [24]:

$$
d_{i j}=\left\langle\bigcup_{r_{i j}^{f} \in \in_{i j}^{f}, \eta_{i j}^{f} \in g_{i j}^{f}}\left\{\left\{1-\prod_{f=1}^{k}\left(1-r_{i j}^{f}\right)^{\lambda_{f}}\right\},\left\{\prod_{f=1}^{k}\left(\eta_{i j}^{f}\right)^{\lambda_{f}}\right\}\right\}\right) .
$$

$$
\begin{aligned}
& r^{+}=\left(r_{i 1}^{+}, r_{i 2}^{+}, \cdots, r_{i n}^{+}\right), \quad(i=1,2, \cdots, m), \\
& r^{-}=\left(r_{i 1}^{-}, r_{i 2}^{-}, \cdots, r_{i n}^{-}\right), \quad(i=1,2, \cdots, m) .
\end{aligned}
$$

For the benefit attributes, $r_{i j}^{+}=\max _{1 \leq i \leq m} d_{i j}$ and $r_{i j}^{-}=\min _{1 \leq i \leq m} d_{i j}$, the attribute values $d_{i j}$ can be compared by the score function $S\left(d_{i j}\right)$ and the accuracy function $P\left(d_{i j}\right)$ according to Theorem 1 . 
Step 3. Calculating positive and negative target-eye distances based on $r^{+}$and $r^{-}$, and the positive and negative target-eye distances of each alternative are calculated using the following equations:

$$
\begin{aligned}
& \zeta_{i j}^{+}=\sqrt{\omega_{1} d_{i 1}^{+2}+\omega_{2} d_{i 2}^{+2}+\cdots+\omega_{n} d_{i n}^{+2}}, \quad(i=1,2, \cdots, m), \\
& \zeta_{i j}^{-}=\sqrt{\omega_{1} d_{i 1}^{-2}+\omega_{2} d_{i 2}^{-2}+\cdots+\omega_{n} d_{i n}^{-2}}, \quad(i=1,2, \cdots, m),
\end{aligned}
$$

where $\left\{\omega_{1}, \omega_{2}, \cdots, \omega_{n}\right\}$ denote the attribute weight vector. $d_{i j}^{+}=d\left(d_{i j}, r_{i j}^{+}\right)$and $d_{i j}^{-}=d\left(d_{i j}, r_{i j}^{-}\right)$denote the normalized Hamming distances between the DHFEs $d_{i j}$ to $r_{i j}^{+}$and $r_{i j}^{-}$, respectively.

Step 4. Calculating comprehensive target-eye distance: the evaluation vector of each alternative is always between the positive and negative clouts. Luo and Wang [28] proved that the optimal solution can be obtained based on $r_{i o}^{*}$ which is on the line between positive and negative clouts. Obviously, the larger $r_{i o}^{*}$, the better the corresponding scheme. The projection $r_{i o}^{*}$ is the comprehensive target-eye distance, and $r_{i o}^{*}$ can be calculated by the following equation:

$$
r_{i o}^{*}=\left|\frac{\left(\zeta_{i j}^{+}\right)^{2}+\left(\zeta^{0}\right)^{2}-\left(\zeta_{i j}^{-}\right)^{2}}{\zeta^{0}}\right|,
$$

where $\zeta^{0}$ is the distance between positive clout $\zeta_{i j}^{+}$and negative clout $\zeta_{i j}^{-}, \zeta^{0}=d\left(\zeta_{i j}^{+}, \zeta_{i j}^{-}\right)$, which can be calculated according to equation (6).

In traditional grey target decision methods, $r_{i o}^{*}$ can be directly calculated when the attribute weights are known. Then, the alternatives can be sorted by $r_{i o}^{*}$. In the case of unknown attribute weight, the method that how to establish the model to solve the optimal initial weight vector is to be given as follows.

Step 5. Optimization of initial attribute weights $\omega^{0}$ : if the weight sequence $\omega=\left(\omega_{1}, \omega_{2}, \cdots, \omega_{n}\right)$ is unknown, the sequence is the grey connotative sequence, and the grey entropy can be defined as

$$
H_{\otimes}(\omega)=-\sum_{s=1}^{n} \omega_{s} \ln \omega_{s}
$$

According to the maximum entropy principle, $\omega_{s}(1,2, \cdots, n)$ should be adjusted to minimize the sequence uncertainty of $\omega^{0}=\left(\omega_{1}, \omega_{2}, \cdots, \omega_{n}\right)$ and maximize $H_{\otimes}(\omega)$. At the same time, considering the proximity between the effect measure of each scheme and the positive clout, the distance between the positive and negative clouts is minimized, and the optimization model is proposed as follows:

$$
\left\{\begin{array}{l}
\min \sum_{i=1}^{m} \sum_{j=1}^{n} r_{i o}^{*}, \\
\max H_{\otimes}(\omega)=-\sum_{s=1}^{n} \omega_{s} \ln \omega_{s}, \\
\sum_{s=1}^{n} \omega_{s}=1, \\
0 \leq \omega_{s} \leq 1, \quad \forall s=1,2, \cdots, n .
\end{array}\right.
$$

Let $f_{1}(\omega)=\sum_{i=1}^{m} \sum_{j=1}^{n} r_{i o}^{*}$ and $f_{2}(\omega)=\sum_{s=1}^{n} \omega_{s} \ln \omega_{s}$; $f_{1}^{\max }(\omega)$ and $f_{1}^{\min }(\omega)$ are the maximum and minimum values of $f_{1}(\omega)$, respectively; $f_{2}^{\max }(\omega)$ and $f_{2}^{\min }(\omega)$ are the maximum and minimum values of $f_{2}(\omega)$, respectively. The two targets are dimensionless. Then, the above multiobjective optimization problems can be transformed into the following single-objective optimization problem:

$$
\left\{\begin{array}{l}
\min \lambda\left[\frac{f_{1}(\omega)-f_{1}^{\min }(\omega)}{f_{1}^{\max }(\omega)-f_{1}^{\min }(\omega)}\right]+(1-\lambda)\left[\frac{f_{2}(\omega)-f_{2}^{\min }(\omega)}{f_{2}^{\max }(\omega)-f_{2}^{\min }(\omega)}\right] \\
\sum_{s=1}^{n} \omega_{s}=1, \\
0 \leq \omega_{s} \leq 1, \quad \forall s=1,2, \cdots, n, \\
0 \leq \lambda \leq 1 .
\end{array}\right.
$$

In view of the fair competition of optimizing objective functions, usually set $\lambda=0.5$ [28]. The optimal initial weight vector can be obtained by using available mathematical programing software. The optimal solution $\omega^{*}$ is the initial weight $\omega^{0}$.

Step 6. Calculating the variable weights: firstly, the relative closeness of alternatives should be calculated by the following equation:

$$
z_{i j}=\frac{d\left(d_{i j}, r_{i j}^{+}\right)}{d\left(d_{i j}, r_{i j}^{+}\right)+d\left(d_{i j}, r_{i j}^{-}\right)} .
$$

Then, let $z_{j}$ be the relative closeness of a positive ideal solution and $S\left(z_{j}\right)$ be the state variable weight vector.

$$
S_{i}\left(z_{j}\right)=\frac{\partial B\left(z_{j}\right)}{\partial z_{i j}} .
$$

In equation (17), $B\left(z_{j}\right)$ is an equilibrium function.

The variable weights can be calculated by the following equation:

$$
w\left(z_{j}\right)=\frac{\omega^{0} \otimes S\left(z_{j}\right)}{\sum_{i} z_{i j}} .
$$


Step 7. Calculating the loss values of attribute weights: taking the initial weight as the reference point, the weight loss matrix of the variable weight vector relative to the initial weight is established as $F$ :

$$
\begin{aligned}
F & =\left[F\left(w_{i}\left(z_{j}\right)\right)\right]_{m \times n} \\
& = \begin{cases}w_{i}\left(z_{j}\right)-w_{i}^{0}, & \text { if } w_{i}\left(z_{j}\right) \geq w_{i}^{0}, \\
-\left(w_{i}^{0}-w_{i}\left(z_{j}\right)\right), & \text { if } w_{i}\left(z_{j}\right) \leq w_{i}^{0},\end{cases}
\end{aligned}
$$

Step 8. Establishing the foreground theory matrix: considering the decision-maker's different risk attitudes towards the gain and loss of weight, the prospect theory matrix is established as

$$
\begin{aligned}
& V\left(w_{i}\left(z_{j}\right)\right) \\
& = \begin{cases}F\left(w_{i}\left(z_{j}\right)\right)^{\partial}, & \text { if } w_{i}\left(z_{j}\right) \geq w_{i}^{0}, \\
-\theta\left(-F\left(w_{i}\left(z_{j}\right)\right)\right)^{\beta}, & \text { if } w_{i}\left(z_{j}\right) \leq w_{i}^{0},\end{cases}
\end{aligned}
$$

Step 9. Ranking the alternatives according to comprehensive target-eye distances, $R_{i o}^{*}$ is calculated based on the variable weight vector and the prospect theory matrix. The most desirable alternative which has a higher value of $R_{i o}^{*}$ should be selected:

$$
R_{i o}^{*}=\sum_{i} V\left(w_{i}\left(z_{j}\right)\right) *\left|r_{i o}^{*}\right| .
$$

In summary, the decision process can be described as Figure 1.

\section{An Example and the Analysis}

4.1. A Numerical Example. In this section, a numerical example is given to present the application of the MAGDM method and to demonstrate its feasibility and effectiveness in a realistic scenario. An investment firm would like to invest four possible alternatives within the volume of total investment. The problem could be resolved through selecting the best options.

Three decision-makers $\left\{\mathrm{DM}_{1}, \mathrm{DM}_{2}, \mathrm{DM}_{3}\right\}$ (the weight vector is $\left.\lambda=(0.25,0.40,0.35)^{T}\right)$ are invited to evaluate the alternatives based on the following three attributes: $C_{j}(j=1,2,3)$, where $C_{1}$ denotes the market share analysis, $C_{2}$ denotes the market growth analysis, and $C_{3}$ denotes the benefit analysis. In this case, all attributes are positive. The attribute weight vector is unknown. The four possible alternatives $A_{i}(i=1,2,3,4)$ are evaluated by using the DHFEs under the above three attributes; then, the dual hesitant fuzzy decision matrices $D f=\left(d_{i j}^{f}\right)_{4 \times 3} \quad(i=1,2,3,4$; $j=1,2,3$; and $f=1,2,3)$ are constructed as shown in Tables $1-3$.

(1) Aggregating all individual dual hesitant fuzzy decision matrices $D f=\left(d_{i j}^{f}\right)_{4 \times 3}(i=1,2,3,4 ; j=1,2,3$; and $f=1,2,3)$ into the collective dual hesitant fuzzy decision matrix $D=\left(d_{i j}\right)_{4 \times 3}$ by equation (7): $d_{11}=\left\{\begin{array}{lllll}0.4113, & 0.4767, & 0.5160, & 0.5201, & 0.5734,\end{array}\right.$ $0.6054,0.4375,0.5000,0.5376,0.5415,0.5924$, $0.6230,0.4680,0.5271,0.5627,0.5663,0.6145$, $0.6435],[0.2213,0.2551,0.2603,0.3000,0.2378$, $0.2741,0.2797,0.3224]\}$.

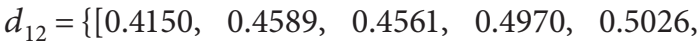
$0.5399,0.4622,0.5026,0.5000,0.5376,0.5427$, 0.5771 ], [ $0.1569,0.2305,0.1845,0.2711,0.1737$, $0.2551,0.2042,0.3000]\}$.

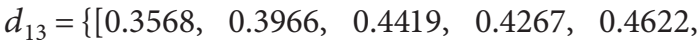
$0.5026,0.4671,0.5000,0.5376,0.3917,0.4293$, $0.4722,0.4578,0.4914,0.5296,0.4960,0.5271$, $0.5627],[0.2280,0.2521,0.2558,0.2828,0.2711$, $0.2998,0.3041,0.3364]\}$.

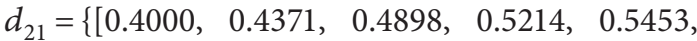
$0.5734,0.4267,0.4622,0.5126,0.5427,0.5655$, $0.5924],[0.2138,0.2312,0.2821,0.3050,0.2297$, $0.2484,0.3031,0.3278]\}$.

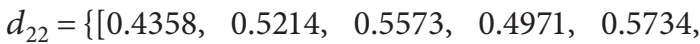
$0.6054,0.4609,0.5427,0.5771,0.5195,0.5924$, $0.6230],[0.1803,0.2297,0.2797,0.3565,0.1906$, $0.2429,0.2958,0.3770]\}$.

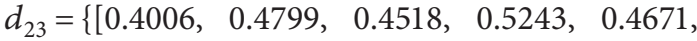
$0.5376,0.5126,0.5771,0.4960,0.5627,0.5390$, $0.6000],[0.2305,0.2549,0.3041,0.3364,0.2741$, $0.3031,0.3617,0.4000]\}$.

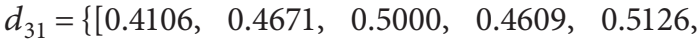
$0.5427,0.4813,0.5309,0.5599,0.5256,0.5710$, $0.5975],[0.2711,0.2998,0.3041,0.3364,0.3000$, $0.3318,0.3366,0.3722]\}$.

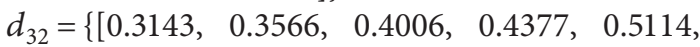
$0.5416,0.3618,0.4013,0.4422,0.4767,0.5453$, $0.5734,0.3903,0.4280,0.4671,0.5000,0.5655$, $0.5924],[0.1677,0.1933,0.2213,0.2551,0.1803$, $0.2077,0.2378,0.2741]\}$.

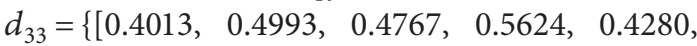
$0.5216,0.5000,0.5819,0.4965,0.5790,0.5599$, $0.6320],[0.2000,0.2305,0.2352,0.2711,0.2213$, $0.2551,0.2603,0.3000]\}$.

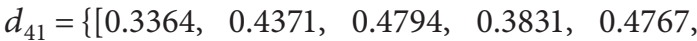
$0.5160,0.4004,0.4914,0.5296,0.4426,0.5271$, $0.5627,0.4958,0.5723,0.6044,0.5313,0.6024$, $0.6322],[0.1978,0.2521,0.2219,0.2828,0.2352$, $0.2998,0.2639,0.3364]\}$.

$d_{42}=\left\{\begin{array}{lllll}0.4419, & 0.4954, & 0.5376, & 0.5819, & 0.5771,\end{array}\right.$ $0.6176,0.4722,0.5228,0.5627,0.6045,0.6000$, $0.6383],[0.1569,0.2305,0.2071,0.3041,0.1866$, $0.2741,0.2462,0.3617]\}$.

$d_{43}=\{[0.4578,0.5296,0.6309,0.4960,0.5627$, $0.6569,0.4955,0.5622,0.6565,0.5309,0.5930$, $0.6807],[0.1741,0.2219,0.1904,0.2426,0.2291$, $0.2921,0.2505,0.3193]\}$.

(2) Identifying the dual hesitant fuzzy positive clout $r^{+}$ and negative clout $r^{-}$of alternatives in the collective dual hesitant fuzzy decision matrix $D$ by equations (8) and (9), respectively:

$r^{+}=(<\{0.4113,0.4767, \quad 0.5160,0.5201,0.5734$, $0.6054,0.4375,0.5000,0.5376,0.5415,0.5924$, 


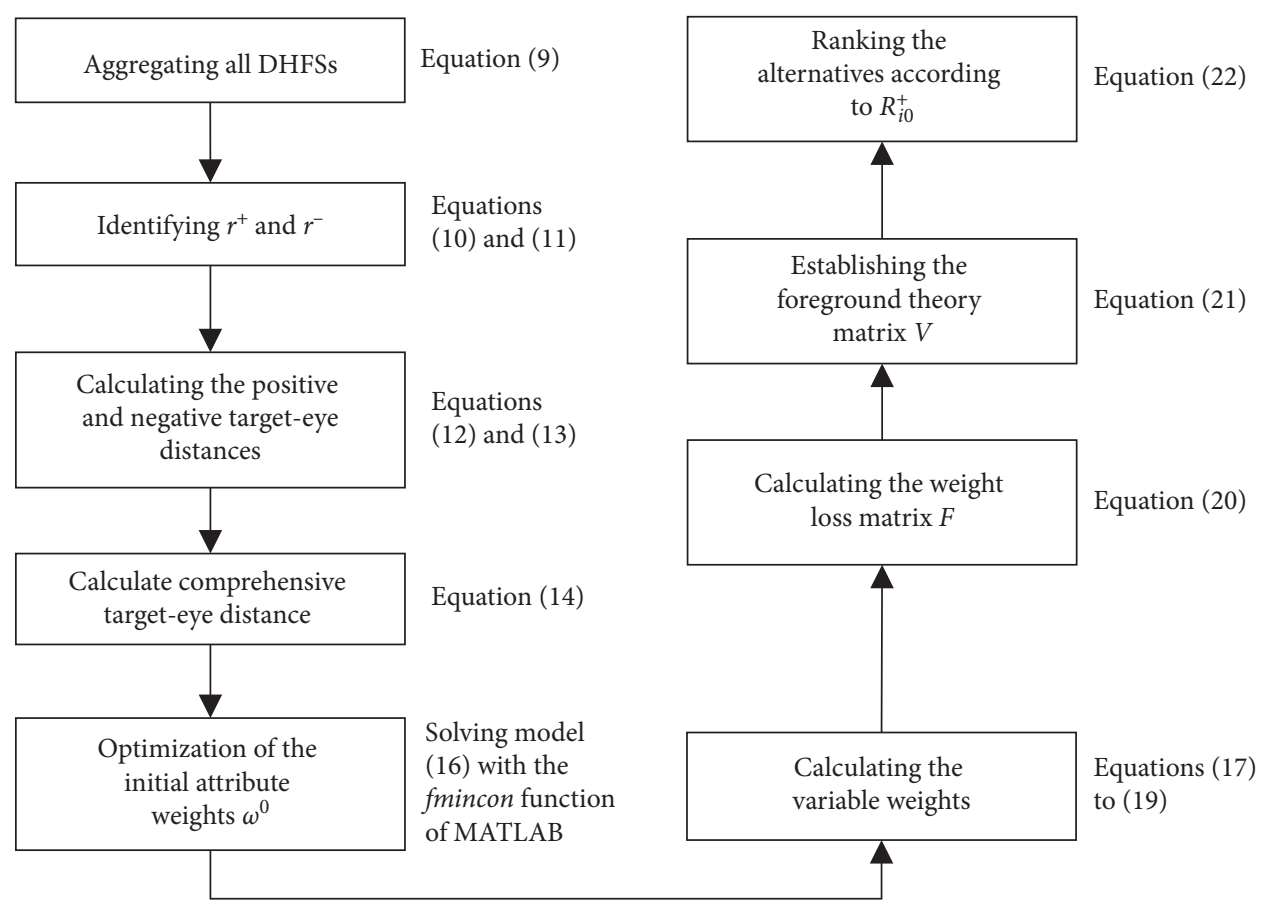

Figure 1: Decision flow of the proposed method.

TABLE 1: Dual hesitant fuzzy decision matrix $D_{1}$ given by $\mathrm{DM}_{1}$.

\begin{tabular}{lccc}
\hline & C1 & C2 & C3 \\
\hline A1 & A1 & $\left\{\left[\begin{array}{llll}0.4 & 0.5 & 0.6\end{array}\right],\left[\begin{array}{lll}0.3 & 0.4\end{array}\right]\right\}$ & $\left\{\left[\begin{array}{lll}0.3 & 0.5\end{array}\right],\left[\begin{array}{ll}0.2 & 0.3\end{array}\right]\right\}$ \\
A2 & A2 & $\left\{\left[\begin{array}{lll}0.4 & 0.5\end{array}\right],\left[\begin{array}{lll}0.3 & 0.4\end{array}\right]\right\}$ & $\left\{\left[\begin{array}{ll}0.4 & 0.5\end{array}\right],\left[\begin{array}{ll}0.4 & 0.5\end{array}\right]\right\}$ \\
A3 & A3 & $\left\{\left[\begin{array}{lll}0.5 & 0.7\end{array}\right],\left[\begin{array}{lll}0.2 & 0.3\end{array}\right]\right\}$ & $\left.\left\{\begin{array}{lll}0.2 & 0.4 & 0.5\end{array}\right],\left[\begin{array}{ll}0.3 & 0.4\end{array}\right]\right\}$ \\
A4 & A4 & $\left\{\left[\begin{array}{lll}0.4 & 0.6 & 0.8\end{array}\right],\left[\begin{array}{ll}0.1 & 0.2\end{array}\right]\right\}$ & $\left.\left\{\begin{array}{lll}0.5 & 0.6\end{array}\right],\left[\begin{array}{ll}0.2 & 0.4\end{array}\right]\right\}$ \\
\hline
\end{tabular}

Data source: Yang and Ju [45].

TABLe 2: Dual hesitant fuzzy decision matrix $D_{2}$ given by $\mathrm{DM}_{2}$.

\begin{tabular}{|c|c|c|c|}
\hline & $\mathrm{C} 1$ & $\mathrm{C} 2$ & $\mathrm{C} 3$ \\
\hline A1 & A1 & $\left\{\left[\begin{array}{ll}0.5 & 0.7\end{array}\right],\left[\begin{array}{ll}0.2 & 0.3\end{array}\right]\right\}$ & $\left\{\left[\begin{array}{llll}0.4 & 0.5 & 0.6\end{array},\left[\begin{array}{lll}0.2 & 0.3\end{array}\right]\right\}\right.$ \\
\hline A2 & A2 & $\left\{\left[\begin{array}{lll}0.4 & 0.6 & 0.7\end{array}\right],\left[\begin{array}{ll}0.1 & 0.2\end{array}\right]\right\}$ & $\left\{\left[\begin{array}{ll}0.6 & 0.7\end{array}\right],\left[\begin{array}{ll}0.1 & 0.3\end{array}\right]\right\}$ \\
\hline A3 & A3 & $\left\{\left[\begin{array}{ll}0.5 & 0.6\end{array}\right],\left[\begin{array}{ll}0.3 & 0.4\end{array}\right]\right\}$ & $\left\{\left[\begin{array}{lll}0.3 & 0.5 & 0.7\end{array}\right],\left[\begin{array}{ll}0.1 & 0.2\end{array}\right]\right\}$ \\
\hline A4 & A4 & $\left\{\left[\begin{array}{ll}0.4 & 0.5\end{array}\right],\left[\begin{array}{ll}0.3 & 0.4\end{array}\right]\right\}$ & $\left\{\left[\begin{array}{lll}0.2 & 0.5 & 0.6\end{array}\right],\left[\begin{array}{ll}0.2 & 0.4\end{array}\right]\right\}$ \\
\hline
\end{tabular}

Data source: Yang and Ju [45].

TABle 3: Dual hesitant fuzzy decision matrix $D_{3}$ given by $\mathrm{DM}_{2}$.

\begin{tabular}{|c|c|c|c|}
\hline & $\mathrm{C} 1$ & $\mathrm{C} 2$ & $\mathrm{C} 3$ \\
\hline $\mathrm{A} 1$ & $\left\{\left[\begin{array}{lll}0.3 & 0.5 & 0.6\end{array}\right],\left[\begin{array}{lll}0.2 & 0.3\end{array}\right\}\right.$ & $\left\{[0.5,0.6],\left[\begin{array}{ll}0.1 & 0.2\end{array}\right]\right\}$ & $\left\{\left[\begin{array}{lll}0.4 & 0.5 & 0.6\end{array}\right],\left[\begin{array}{ll}0.3 & 0.4\end{array}\right]\right\}$ \\
\hline A2 & $\left\{\left[\begin{array}{ll}0.4 & 0.5\end{array}\right],\left[\begin{array}{ll}0.4 & 0.5\end{array}\right]\right\}$ & $\left\{\left[\begin{array}{lll}0.2 & 0.5 & 0.6\end{array}\right],\left[\begin{array}{ll}0.2 & 0.4\end{array}\right]\right\}$ & $\left\{\left[\begin{array}{ll}0.4 & 0.6\end{array}\right],\left[\begin{array}{ll}0.3 & 0.4\end{array}\right]\right\}$ \\
\hline A3 & $\left\{\left[\begin{array}{lll}0.2 & 0.4 & 0.5\end{array}\right],\left[\begin{array}{ll}0.3 & 0.4\end{array}\right]\right\}$ & $\left\{\left[\begin{array}{ll}0.4 & 0.5\end{array}\right],\left[\begin{array}{ll}0.2 & 0.3\end{array}\right]\right\}$ & $\left\{\left[\begin{array}{ll}0.6 & 0.7\end{array}\right],\left[\begin{array}{ll}0.2 & 0.3\end{array}\right]\right\}$ \\
\hline A4 & $\left\{\left[\begin{array}{lll}0.2 & 0.5 & 0.6\end{array}\right],\left[\begin{array}{ll}0.2 & 0.4\end{array}\right]\right\}$ & $\left\{\left[\begin{array}{ll}0.6 & 0.7\end{array}\right],\left[\begin{array}{ll}0.1 & 0.3\end{array}\right]\right\}$ & $\left\{\left[\begin{array}{lll}0.4 & 0.6 & 0.8\end{array}\right],\left[\begin{array}{ll}0.1 & 0.2\end{array}\right]\right\}$ \\
\hline
\end{tabular}

Data source: Yang and Ju [45].

$0.6230,0.4680,0.5271,0.5627,0.5663,0.6145$, $0.6435\},\{0.2213,0.2551,0.2603,0.3000,0.2378$, $0.2741,0.2797,0.3224\}>,<\{0.4419,0.4954,0.5376$, $0.5819,0.5771,0.6176,0.4722,0.5228,0.5627$, $0.6045,0.6000,0.6383\},\{0.1569,0.2305,0.2071$,
$0.3041,0.1866,0.2741,0.2462,0.3617\}>,<\{0.4578$, $0.5296,0.6309,0.4960,0.5627,0.6569,0.4955$, $0.5622,0.6565,0.5309,0.5930,0.6807\},\{0.1741$, $0.2219,0.1904,0.2426,0.2291,0.2921,0.2505$, $0.3193\}>)$. 
$r^{-}=(<\{0.4106, \quad 0.4671, \quad 0.5000,0.4609,0.5126$, $0.5427,0.4813,0.5309,0.5599,0.5256,0.5710$, $0.5975\},\{0.2711,0.2998,0.3041,0.3364,0.3000$, $0.3318,0.3366,0.3722\}>,<\{0.3143,0.3566,0.4006$, $0.4377,0.5114,0.5416,0.3618,0.4013,0.4422$, $0.4767,0.5453,0.5734,0.3903,0.4280,0.4671$, $0.5000,0.5655,0.5924\},\{0.1677,0.1933,0.2213$, $0.2551,0.1803,0.2077,0.2378,0.2741\}>,<\{0.3568$, $0.3966,0.4419,0.4267,0.4622,0.5026,0.4671$,
$0.5000,0.5376,0.3917,0.4293,0.4722,0.4578$, $0.4914,0.5296,0.4960,0.5271,0.5627\},\{0.2280$, $0.2521,0.2558,0.2828,0.2711,0.2998,0.3041$, $0.3364\}>)$.

(3) Calculating the positive and negative target-eye distances of each alternative from $r^{+}$and $r^{-}$by equations (10) and (11), respectively:

$$
\begin{aligned}
& \zeta_{i j}^{+}=\left(\begin{array}{c}
\sqrt{0 * \omega_{1}+0.0016 \omega_{2}+0.0049 \omega_{3}}, \sqrt{3.1108 e-04 \omega_{1}+3.1204 e-04 \omega_{2}+0.0040 \omega_{3}}, \\
\sqrt{0.0015 \omega_{1}+0.0037 \omega_{2}+8.3702 e-04 \omega_{3}}, \sqrt{5.3528 e-04 \omega_{1}+0 * \omega_{2}+0 * \omega_{3}}
\end{array}\right), \\
& \zeta_{i j}^{-}=\left(\begin{array}{c}
\sqrt{0.0383 \omega_{1}+0.0213 \omega_{2}+0 * \omega_{3}}, \sqrt{0.0295 \omega_{1}+0.0663 \omega_{2}+0.0362 \omega_{3}}, \\
\sqrt{0 * \omega_{1}+0 * \omega_{2}+0.0413 \omega_{3}}, \sqrt{0.0350 \omega_{1}+0.0608 \omega_{2}+0.0702 \omega_{3}}
\end{array}\right) .
\end{aligned}
$$

(4) Calculate comprehensive target-eye distance $r_{i o}^{*}$ by equation (12):

$$
r_{i o}^{*}=\frac{\left(\zeta_{i j}^{+}\right)^{2}+\left(\zeta^{0}\right)^{2}-\left(\zeta_{i j}^{-}\right)^{2}}{\zeta^{0}}
$$

where $\zeta^{0}$ can be calculated by equation (6), $\zeta^{0}=\sqrt{0.0015 * \omega_{1}+0.0037 \omega_{2}+0.0049 \omega_{3}}$.

(5) Optimization of the initial attribute weights $\omega^{0}$ : the fmincon function of MATLAB is used to solve the model, and the optimal weight can be obtained, $\omega^{0}=\left(\omega_{1}, \omega_{2}, \omega_{3}\right)=[0.48230 .36990 .1478]$.

(6) Calculating the variable weights: the relative closeness of alternatives can be calculated by equation (16):

$$
z_{i j}=\left[\begin{array}{ccc}
0 & 0.6490 & 1.0000 \\
0.3744 & 0.2104 & 0.6367 \\
1.0000 & 1.0000 & 0.4121 \\
0.3982 & 0 & 0
\end{array}\right] .
$$

With reference to $[46,47]$, as well as taking $p$ as the reference point, the S-shaped utility curve combined with the preference of decision-makers is constructed as follows:

$$
u(t)=\frac{1}{6} t^{3}-\frac{1}{2} p t^{2}+\left(\frac{5}{6}+\frac{1}{2} p\right) t
$$

Chinese people's decision-making preference is mostly an S-shaped utility curve [44] if $p=0.5$, which is positioned as the following:

$$
u(t)=\frac{1}{6} t^{3}-\frac{1}{4} t^{2}+\frac{13}{12} t
$$

$$
\text { that is, } \omega_{i}\left(z_{j}\right)=\frac{\omega_{i}^{0}\left((1 / 2) z_{i j}^{2}-(1 / 2) z_{i j}+(13 / 12)\right)}{\sum_{l=1}^{n} \omega_{l}^{0}\left((1 / 2) z_{l j}^{2}-(1 / 2) z_{l j}+(13 / 12)\right)} \text {. }
$$

In equation (25), $i=1,2, \cdots, 3$ and $j=1,2, \cdots, 4$.

Then, the variable weights $W$ can be calculated by equation (18):

$$
W=\left[\begin{array}{lll}
0.5018 & 0.3444 & 0.1538 \\
0.4760 & 0.3779 & 0.1461 \\
0.4904 & 0.3761 & 0.1335 \\
0.4531 & 0.3907 & 0.1561
\end{array}\right] .
$$

(7) Calculating the weight loss matrix $F$ by equation (19):

$$
F=\left[\begin{array}{ccc}
0.0195 & -0.0255 & 0.0060 \\
-0.0063 & 0.0080 & -0.0017 \\
0.0081 & 0.0062 & -0.0143 \\
-0.0292 & 0.0208 & 0.0083
\end{array}\right]
$$

(8) Establishing the foreground theory matrix $V$ by equation (20):

$$
V=\left[\begin{array}{ccc}
0.0085 & -0.0533 & 0.0020 \\
-0.0128 & 0.0029 & -0.0034 \\
0.0029 & 0.0021 & -0.0296 \\
-0.0612 & 0.0092 & 0.0030
\end{array}\right] .
$$


TABle 4: Decision results of different reference points.

\begin{tabular}{|c|c|c|c|c|c|c|}
\hline \multirow{2}{*}{ Utility functions } & \multirow{2}{*}{ Reference points } & \multicolumn{4}{|c|}{ Alternatives } & \multirow{2}{*}{ Ranking of alternatives } \\
\hline & & $\xi_{1}$ & $\xi_{2}$ & $\xi_{3}$ & $\xi_{4}$ & \\
\hline Risky utility function & $p=0$ & $\begin{array}{l}-0.0179 \\
-00505\end{array}$ & $\begin{array}{l}-0.0101 \\
-0.0265\end{array}$ & $\begin{array}{l}-0.0005 \\
-0.0014\end{array}$ & $\begin{array}{l}-0.0430 \\
-0.0321\end{array}$ & $\begin{array}{l}A_{3}>A_{2}>A_{1}>A_{4} \\
A>A\end{array}$ \\
\hline S-shaped utility functions & $\begin{array}{l}p=0.25 \\
p=0.5 \\
p=0.75\end{array}$ & $\begin{array}{l}-0.0505 \\
-0.0427 \\
-0.0406\end{array}$ & $\begin{array}{l}-0.0265 \\
-0.0515 \\
-0.0254\end{array}$ & $\begin{array}{l}-0.0014 \\
-0.0406 \\
-0.0001\end{array}$ & $\begin{array}{l}-0.0321 \\
-0.1100 \\
-0.0720\end{array}$ & $\begin{array}{l}A_{3}>A_{2}>A_{4}>A_{1} \\
A_{3}>A_{1}>A_{2}>A_{4} \\
A_{3}>A_{2}>A_{1}>A_{4}\end{array}$ \\
\hline Conservative utility function & $p=1$ & -0.0652 & -0.0392 & -0.0008 & -0.0967 & $A_{3}>A_{2}>A_{1}>A_{4}$ \\
\hline
\end{tabular}

TABLE 5: Decision results of different methods.

\begin{tabular}{lc}
\hline Methods & Ranking of alternatives \\
\hline Gupta et al. [27] & $A_{4}>A_{2}>A_{1}>A_{3}$ \\
Wei et al. [43] & $A_{4}>A_{2}>A_{1}>A_{3}$ \\
This article: not considering decision-maker's loss aversion & $A_{4}>A_{2}>A_{1}>A_{3}$ \\
This article: considering decision-maker's loss aversion $(p=0.5)$ & $A_{3}>A_{1}>A_{2}>A_{4}$ \\
This article: considering decision-maker's loss aversion $(p=0.75)$ & $A_{3}>A_{2}>A_{1}>A_{4}$ \\
\hline
\end{tabular}

(9) Ranking the alternatives according to $R_{i o}^{*}$.

$R_{i o}^{*}$ is calculated by equation (21), and $R_{i o}^{*}=$ [ $-0.0427-0.0515-0.0406-0.1100]$.

The alternatives can be ranked according to $R_{i o}^{*}$; thus, $A_{3}>A_{1}>A_{2}>A_{4}$. Therefore, the most desirable alternative is $A_{3}$.

4.2. The Sensitivity Analysis. In order to illustrate the influence of reference points on decision results, the sensitivity analysis results are shown in Table 4 by changing the values of $p$ and repeating Steps (6) to (9). As can be seen from Table 4, in all the utility functions, the optimal alternative is the same, but the ranking of evaluation results at different reference points is different. Therefore, this method fully reflects the flexibility of the process and the limited rationality of the decision-maker.

4.3. Comparison and Analysis with Previous Methods. Compared with the grey target decision method proposed in [27] and the grey relational analysis (GRA) method based on DHFS proposed in [43], the comparison results are shown in Table 5. At the same time, an ablation study is given to analyze the impact of decision-maker's loss aversion on results. We calculate the results of the grey target decision method with positive and negative clouts without considering the loss aversion factor of decision-makers. The tackle method is described as follows. Calculating Step 1 to Step 5 in Section 3, and then substituting the weight calculated in Step 5 into Step 4 to get $r_{i o}^{*}$; the alternatives can be sorted by $r_{i o}^{*}$. The results show that, without considering the decisionmaker's loss aversion, the decision results obtained by the three methods are the same. The reliability of the grey target decision method with positive and negative clouts and the DHFS proposed in this article is proved. After considering the decision-maker's loss aversion, the sorting results changed. Then, the decision results reflect the limited rationality and preference of decision-makers.

\section{Conclusions}

In this paper, a novel MAGDM problem based on the grey target decision method with positive and negative clouts under the dual hesitant fuzzy environment is proposed. An optimization model is established, which is employed to determine the initial weight vector of attributes. The optimization model is constructed with considering the proximity between the effect measures of alternatives, the positive ideal value, and the uncertainty of the attribute weight. The alternatives are sorted according to the comprehensive target-eye distance. Finally, a numerical example is presented to illustrate the application of the proposed method. The method provides a scientific and practical decision support to solve the MAGDM problem with double hesitation fuzzy numbers and decision-maker's loss aversion. This study is limited in that it cannot solve some new DHFSs, such as the probabilistic dual hesitant fuzzy set (PDHFS). Further research can introduce multiple new DHFSs to study the grey target group decision method.

\section{Data Availability}

The data used to support the findings of this study are included within the article.

\section{Conflicts of Interest}

The authors declare no conflicts of interest.

\section{Acknowledgments}

This research was supported by the Social Sciences Foundation of Chongqing Municipality (no. 2016BS034), the National Natural Science Foundation of China (no. 71702015), the National Social Sciences Foundation of China (no. 18BGL007), the China Postdoctoral Science Foundation (no. 2017M611810), the Research Platform Open Project in CTBU (no. KFJJ2018079), Humanities and Social Sciences Research Program of Chongqing Education Commission 
(no.18SKGH063), Science and Technology Research Projects of Chongqing Education Commission (no. KJQN201900812), and Technology Foresight and System Innovation Project of Chongqing Municipality (no. cstc2019jsyj-zzysbax0066).

\section{References}

[1] I. Deli and Y. Şubaş, "A ranking method of single valued neutrosophic numbers and its applications to multi-attribute decision making problems," International Journal of Machine Learning and Cybernetics, vol. 8, no. 4, pp. 1309-1322, 2017.

[2] H.-B. Yan, T. Ma, and V.-N. Huynh, "On qualitative multiattribute group decision making and its consensus measure: a probability based perspective," Omega, vol. 70, pp. 94-117, 2017.

[3] S. Singh and M. Dasgupta, "Evaluation of research on CO 2 trans-critical work recovery expander using multi attribute decision making methods," Renewable and Sustainable Energy Reviews, vol. 59, pp. 119-129, 2016.

[4] W. Zhao, L. Yan, and Y. Zhang, "Geometric-constrained multi-view image matching method based on semi-global optimization," Geo-spatial Information Science, vol. 21, no. 2, pp. 115-126, 2016.

[5] Z. S. Abdallah, M. M. Gaber, B. Srinivasan, and S. Krishnaswamy, "Adaptive mobile activity recognition system with evolving data streams," Neurocomputing, vol. 150, pp. 304-317, 2015.

[6] M. S. Bakli, M. A. Sakr, and T. H. A. Soliman, "A spatiotemporal algebra in Hadoop for moving objects," Geo-Spatial Information Science, vol. 21, no. 2, pp. 102-114, 2018.

[7] M. M. Awad, "Forest mapping: a comparison between hyperspectral and multispectral images and technologies," Journal of Forestry Research, vol. 29, no. 5, pp. 1395-1405, 2017.

[8] A. Jalal, M. A. K. Quaid, and A. S. Hasan, "Wearable sensorbased human behavior understanding and recognition in daily life for smart environments," in Proceedings of the 2018 International Conference on Frontiers of Information Technology (FIT), Islamabad, Pakistan, December 2018.

[9] A. Jalal, S. Kamal, and D. Kim, "A depth video sensor-based life-logging human activity recognition system for elderly care in smart indoor environments," Sensors, vol. 14, no. 7, pp. 11735-11759, 2014.

[10] P. Biswas, S. Pramanik, and B. C. Giri, "TOPSIS method for multi-attribute group decision-making under single-valued neutrosophic environment," Neural Computing and Applications, vol. 27, no. 3, pp. 727-737, 2016.

[11] X. Zhang and J. Su, "A combined fuzzy DEMATEL and TOPSIS approach for estimating participants in knowledgeintensive crowdsourcing," Computers \& Industrial Engineering, vol. 137, Article ID 106085, 2019.

[12] Q. Pang, H. Wang, and Z. Xu, "Probabilistic linguistic term sets in multi-attribute group decision making," Information Sciences, vol. 369, pp. 128-143, 2016.

[13] A. Jalal, Y.-H. Kim, Y.-J. Kim, S. Kamal, and D. Kim, "Robust human activity recognition from depth video using spatiotemporal multi-fused features," Pattern Recognition, vol. 61, pp. 295-308, 2017.

[14] L. M. G. Fonseca, L. M. Namikawa, and E. F. Castejon, "Digital image processing in remote sensing," in Proceedings of the 2009 Tutorials of the XXII Brazilian Symposium on Computer Graphics and Image Processing, Rio de Janeiro, Brazil, October 2009.
[15] S. Kamal, A. Jalal, and D. Kim, "Depth images-based human detection, tracking and activity recognition using spatiotemporal features and modified HMM," Journal of Electrical Engineering and Technology, vol. 11, no. 6, pp. 1857-1862, 2016.

[16] K. Buys, C. Cagniart, A. Baksheev, T. De Laet, J. De Schutter, and C. Pantofaru, "An adaptable system for RGB-D based human body detection and pose estimation," Journal of Visual Communication and Image Representation, vol. 25, no. 1, pp. 39-52, 2014.

[17] A. Prochazka, M. Kolinova, J. Fiala, P. Hampl, and K. Hlavaty, "Satellite image processing and air pollution detection," in 2000 IEEE International Conference on Acoustics, Speech, and Signal Processing. Proceedings (Cat. No.00CH37100), Istanbul, Turkey, June 2000.

[18] M. M. U. Rathore, A. Ahmad, A. Paul, and J. Wu, "Real-time continuous feature extraction in large size satellite images," Journal of Systems Architecture, vol. 64, pp. 122-132, 2016.

[19] A. Farooq, A. Jalal, and S. Kamal, "Dense RGB-D map-based human tracking and activity recognition using skin joints features and self-organizing map," KSII Transactions on Internet \& Information Systems, vol. 9, no. 5, 2015.

[20] Q. Huang, J. Yang, and Y. Qiao, "Person re-identification across multi-camera system based on local descriptors," in Proceedings of the 2012 Sixth International Conference on Distributed Smart Cameras (ICDSC), IEEE, Hong Kong, China, pp. 1-6, 2012, October.

[21] S. Kamal and A. Jalal, "A hybrid feature extraction approach for human detection, tracking and activity recognition using depth sensors," Arabian Journal for Science and Engineering, vol. 41, no. 3, pp. 1043-1051, 2015.

[22] H. Yoshimoto, N. Date, and S. Yonemoto, "Vision-based realtime motion capture system using multiple cameras," in Proceedings of the IEEE International Conference on Multisensor Fusion and Integration for Intelligent Systems, MFI2003, Tokyo, Japan, August 2003.

[23] L. Piyathilaka and S. Kodagoda, "Gaussian mixture based HMM for human daily activity recognition using 3D skeleton features," in Proceedings of the 2013 IEEE 8th Conference on Industrial Electronics and Applications (ICIEA), Melbourne, Australia, June 2013.

[24] A. Jalal, M. A. Quaid, and M. A. Sidduqi, "A Triaxial acceleration-based human motion detection for ambient smart home system," in Proceedings of the 2019 16th International Bhurban Conference on Applied Sciences and Technology (IBCAST), pp. 353-358, IEEE, Islamabad, Pakistan, 2019 January.

[25] A. Jalal, S. Kamal, and D. Kim, "Individual detection-tracking-recognition using depth activity images," in Proceedings of the 2015 12th International Conference on Ubiquitous Robots and Ambient Intelligence (URAI), Goyang, Republic of Korea, October 2015.

[26] H. Wu, W. Pan, X. Xiong, and S. Xu, "Human activity recognition based on the combined SVM\&HMM," in Proceedings of the 2014 IEEE International Conference on Information and Automation (ICIA), Hailar, China, July 2014.

[27] P. Gupta, M. K. Mehlawat, N. Grover, and W. Pedrycz, "Multi-attribute group decision making based on extended TOPSIS method under interval-valued intuitionistic fuzzy environment," Applied Soft Computing, vol. 69, pp. 554-567, 2018.

[28] D. Luo and X. Wang, "The multi-attribute grey target decision method for attribute value within three-parameter interval grey number," Applied Mathematical Modelling, vol. 36, no. 5, pp. 1957-1963, 2012. 
[29] Y. Wang, X. Shi, J. Sun, and W. Qian, “A grey interval relational degree-based dynamic multiattribute decision making method and its application in investment decision making," Mathematical Problems in Engineering, vol. 2014, Article ID 307586, 6 pages, 2014.

[30] W. Qian, X. Yang, and J. Li, "Grey target decision model based on interval grey number type panel data and its application," Journal of Grey System, vol. 30, no. 1, pp. 69-80, 2018.

[31] F. Ye, "An extended TOPSIS method with interval-valued intuitionistic fuzzy numbers for virtual enterprise partner selection," Expert Systems with Applications, vol. 37, no. 10, pp. 7050-7055, 2010.

[32] S. Fu, G. Sun, and Y. Xiao, "Multi-attribute decision-making model of grey target for information system evaluation," Computer Science and Information Technology, vol. 4, no. 1, pp. 15-20, 2016.

[33] B. Zeng, C. Li, and S.-F. Liu, "A novel grey target decisionmaking model based on cobweb area and its application for choosing the software development pattern," Scientia Iranica, vol. 23, no. 1, pp. 361-373, 2016.

[34] R. M. Rodriguez, L. Martinez, and F. Herrera, "Hesitant fuzzy linguistic term sets for decision making," IEEE Transactions on Fuzzy Systems, vol. 20, no. 1, pp. 109-119, 2012.

[35] B. Zhu, Z. Xu, and M. Xia, "Dual hesitant fuzzy sets," Journal of Applied Mathematics, vol. 2012, Article ID 879629, 13 pages, 2012.

[36] H. Wang, X. Zhao, and G. Wei, "Dual hesitant fuzzy aggregation operators in multiple attribute decision making," Journal of Intelligent \& Fuzzy Systems, vol. 26, no. 5, pp. 2281-2290, 2014.

[37] L. Wang, Q. Shen, and L. Zhu, "Dual hesitant fuzzy power aggregation operators based on Archimedean t-conorm and $\mathrm{t}$-norm and their application to multiple attribute group decision making," Applied Soft Computing, vol. 38, pp. 23-50, 2016.

[38] Y. Xing, R. Zhang, M. Xia, and J. Wang, "Generalized point aggregation operators for dual hesitant fuzzy information," Journal of Intelligent \& Fuzzy Systems, vol. 33, no. 1, pp. 515-527, 2017.

[39] D. Yu, W. Zhang, and G. Huang, "Dual hesitant fuzzy aggregation operators," Technological and Economic Development of Economy, vol. 22, no. 2, pp. 194-209, 2016.

[40] J. Yang, J. Su, and L. Song, "Selection of manufacturing enterprise innovation design Project based on consumer's green preferences," Sustainability, vol. 11, no. 5, p. 1375, 2019.

[41] Z. Ren and C. Wei, "A multi-attribute decision-making method with prioritization relationship and dual hesitant fuzzy decision information," International Journal of Machine Learning and Cybernetics, vol. 8, no. 3, pp. 755-763, 2017.

[42] Z. Ren, Z. Xu, and H. Wang, "Dual hesitant fuzzy VIKOR method for multi-criteria group decision making based on fuzzy measure and new comparison method," Information Sciences, vol. 388-389, pp. 1-16, 2017.

[43] G.-W. Wei, X.-R. Xu, and D.-X. Deng, "Interval-valued dual hesitant fuzzy linguistic geometric aggregation operators in multiple attribute decision making," International Journal of Knowledge-Based and Intelligent Engineering Systems, vol. 20, no. 4, pp. 189-196, 2016.

[44] M. Lu and G.-W. Wei, "Models for multiple attribute decision making with dual hesitant fuzzy uncertain linguistic information," International Journal of Knowledge-Based and Intelligent Engineering Systems, vol. 20, no. 4, pp. 217-227, 2016.

[45] S. Yang and Y. Ju, "A GRA method for investment alternative selection under dual hesitant fuzzy environment with incomplete weight information," Journal of Intelligent \& Fuzzy Systems, vol. 28, no. 4, pp. 1533-1543, 2015.

[46] G. F. Yu, D. F. Li, J. Wu, and Y. F. Ye, "Heterogeneous multiattribute variable weight decision making method considering decision maker's loss aversion," Chinese Journal of Management Science, vol. 26, no. 9, pp. 141-147, 2018.

[47] Y. F. Zhou and N. Chen, "The LAP under facility disruptions during early post-earthquake rescue using PSO-GA hybrid algorithm," Fresenius Environmental Bulletin, vol. 28, no. 12, pp. 9906-9914, 2019. 